Article

\title{
Glycyrrhetinic Acid Liposomes and Hyalurosomes on Spanish Broom, Flax, and Hemp Dressings to Heal Skin Wounds
}

\author{
Angela Abruzzo, Concettina Cappadone, Giovanna Farruggia, Barbara Luppi *, Federica Bigucci \\ and Teresa Cerchiara
}

Department of Pharmacy and Biotechnology, Alma Mater Studiorum-University of Bologna, Via San Donato 19/2, 40127 Bologna, Italy; angela.abruzzo2@unibo.it (A.A.); concettina.cappadone@unibo.it (C.C.); giovanna.farruggia@unibo.it (G.F.); federica.bigucci@unibo.it (F.B.); teresa.cerchiara2@unibo.it (T.C.)

* Correspondence: barbara.luppi@unibo.it; Tel.: +39-0512095615

Academic Editor: Rita Cortesi

Received: 28 April 2020; Accepted: 28 May 2020; Published: 31 May 2020

\begin{abstract}
The focus of this work was to prepare Spanish Broom, flax, and hemp dressings impregnated with glycyrrhetinic acid (GA) liposomes or hyalurosomes to promote the healing process and protect the skin wounds. Vesicles were prepared by the film hydration method and characterized in terms of size, particle size distribution, $\zeta$ potential, encapsulation efficiency, in vitro release, and biocompatibility on 3T3 fibroblasts. Loaded liposomes and hyalurosomes showed nanometric size ( $355 \pm 19 \mathrm{~nm}$ and $424 \pm 32 \mathrm{~nm}$, respectively), good size distribution (lower than 0.3 ), and appropriate encapsulation efficiency ( $58.62 \pm 3.25 \%$ and $59.22 \pm 8.18 \%$, respectively). Hyalurosomes showed good stability during the storage period, which can be correlated to the negative $\zeta$ potential, and allowed a fast and complete release of GA. Preliminary biological studies revealed that both kinds of loaded vesicles were not cytotoxic and that hyalurosomes could exert a slight stimulating effect on fibroblast proliferation. Finally, in vitro release studies from the different dressings impregnated with the loaded vesicles demonstrated that a high amount of GA could be reached at the wound site after $60 \mathrm{~min}$ from application. In conclusion, the results suggested that the developed dressings, especially those impregnated with hyalurosomes, can be efficiently used to promote the healing process.
\end{abstract}

Keywords: wound dressing; glycyrrhetinic acid; liposomes; hyalurosomes; cytotoxicity; Spanish Broom; flax; hemp

\section{Introduction}

In recent years, the focus of wound-care has been based on research and development of new antibacterial and anti-inflammatory wound dressings able to improve and accelerate the healing process. This process is based on four different phases including hemostasis, which occurs immediately after injury, followed by the inflammatory phase, the formations of new vessels, and finally the maturation of new tissues [1-3]. The first step in order to effectively heal the wound and to prevent it from any infectious agent requires the cover of the wound by an appropriate material [4]. Traditional wound dressings are textile fibers such as cotton, wool, and silk, but new wound dressing materials are an important part of the rapidly growing biomaterials industry [5].

In this regard, the aim of this study was the development of new Spanish Broom, flax, and hemp wound dressings impregnated with nanosystems containing $18-\beta$-glycyrrhetinic acid (GA) for wound healing management. Spanish Broom, flax, and hemp are bast fibers [6] and can be considered as sustainable and biodegradable alternatives to cotton owing to their availability, renewability, and cleaner and more resilient cultivation. Cotton fibers are the most popular natural fibers, widely 
used in various textile industries. However, its cultivation is environmentally unsustainable owing to use of pesticides and a large amount of water [7]. Spanish Broom, flax, and hemp fibers as well as cotton are composed of cellulose fibers suitable for use in the treatment of wounds as well as in the hygiene sector, owing to their high compatibility with skin and wounds [8]. GA, a pentacyclic triterpenoid found in the Glycyrrhiza glabra L. liquorice roots [9], was selected as bioactive molecule with proven anti-inflammatory, antioxidant, and antimicrobial activity [10-12]. The inhibition of the inflammatory cascade together with the antioxidant mechanism of GA may increase the repair process rate of the damaged skin by restoring the physiological balance and tissue functionality [9]. According to Biopharmaceutical Classification System, GA is a type II drug characterized by low solubility $[13,14]$ and, to overcome this drawback, appropriate formulative strategies such as the encapsulation of GA in nanosystems might be used. In recent years, nanoparticles [15], liposomes [16], and multifunctional nanofibers [17] have been investigated to increase drug solubility and be applied as drug carriers. Among them, liposomes have become promising drug delivery systems for skin wounds thanks to several advantages such as biocompatibility, safety, and ability to be directly applied to the wounds [18].

In order to prepare a performing dressing for wound treatment, we combined the possibility to protect skin wounds using different supporting biomaterials and to deliver at the wound site functional nanosystems able to improve the interaction with the biological substrates, thus promoting the healing process. To the best of our knowledge, this is the first study reporting the use of new dressings based on Spanish Broom, flax, and hemp impregnated with different GA-loaded vesicles. Specifically, GA-loaded liposomes or hyalurosomes were prepared and characterized for their physico-chemical and functional properties, such as size, particle size distribution, $\zeta$ potential, encapsulation efficiency, and ability to release GA. In addition, vesicle cytotoxicity and cell proliferation activity were evaluated through 3-(4,5-dimethylthiazol-2-yl)-2, 5-diphenyl tetrazolium bromide (MTT) assay and cell cycle analysis on 3T3 fibroblasts, respectively. Finally, loaded vesicles were sunk into Spanish Broom, flax, and hemp dressings and in vitro release tests were performed in order to study dressings ability to release GA over time.

\section{Results and Discussion}

In this work, GA-loaded liposomes and hyalurosomes were prepared through the film hydration method followed by extrusion and subsequently sunk into Spanish Broom, flax, or hemp gauzes, by impregnation.

GA, the major active component of licorice root extract, possesses well-documented anti-inflammatory, antimicrobial, and antioxidant properties and could represent a valid approach to treat skin wounds $[9,12]$. However, despite the wide spectrum of beneficial properties, the clinical application of GA has been hampered owing to its low water solubility $[13,14]$. In this context, the development of an adequate formulation, able to improve GA solubility, represents a key challenge for its delivery. Liposomes were selected considering their ability to straightforwardly entrap hydrophobic molecules into phospholipid bilayers and their optimal properties for skin drug delivery [19]. Furthermore, in this work, modified vesicles were also prepared by employing hyaluronic acid sodium salt, a water-soluble polymer possessing, at $\mathrm{pH}$ higher than its pka ( $\approx 2.9)$, negatively charged groups able to stabilize the vesicles [20]. In addition, sodium hyaluronate was selected on the basis of its high biocompatibility and its well-known role in skin wound healing [21].

In order to optimize the application of liposome suspensions on skin wounds, simplify self-medication, and consequently increase patient compliance, a suitable support should be adopted. In this study, taking into account the increasing request to find new biomaterials for wound treatment [22], three different types of wound dressings, Spanish Broom, flax, and hemp, were proposed as alternative to traditional cotton dressing. Spanish Broom fibers were used in our previous studies for the delivery of different active substances in the treatment of skin wounds [7,23], and our findings allowed us to propose them as an attractive and ecologically sustainable alternative for the preparation of dressings for wound care. In this work, Spanish Broom dressings were compared with flax and hemp, 
selected as additional materials for wound dressing on the basis of their interesting characteristics, such as the high hydrophilic nature and the capacity to absorb a large amount of water.

\subsection{Vesicle Characterization}

The main physicochemical properties of liposomes and hyalurosomes are summarized in Table 1. The presence of sodium hyaluronate allowed to obtain vesicles with a larger size with respect to liposomes $(p<0.05)$, probably owing to the polymer ability to interact with the choline groups of phosphatidylcholine and to promote the formation of bigger structures. This result was in agreement with previous findings reported by Castangia and co-workers [12], who attributed the size increase of vesicles containing hyaluronic acid to the absorption of polymer onto their surface and its intercalation between the bilayers. Moreover, the sizes of $\mathrm{LP}_{\mathrm{GA}}$ and HYA $\mathrm{GA}_{\mathrm{GA}}$ were higher $(p<0.05)$ than $\mathrm{LP}$ and HYA, respectively, as a consequence of GA encapsulation inside the bilayers of liposomes.

Table 1. Size (nm), particle size distribution (PSD), $\zeta$ potential $(\mathrm{mV})$, and encapsulation efficiency (EE

$\%$ ) of the different vesicles. HYA, hyalurosome; LP, liposome; GA, glycyrrhetinic acid.

\begin{tabular}{ccccc}
\hline & Size $(\mathbf{n m})$ & PSD & $\zeta$ Potential $(\mathbf{m V})$ & EE\% \\
\hline LP & $270 \pm 7$ & $0.28 \pm 0.06$ & $-47.96 \pm 1.45$ & $/$ \\
LP & $355 \pm 19$ & $0.21 \pm 0.08$ & $-46.72 \pm 1.91$ & $58.62 \pm 3.25$ \\
HYA & $315 \pm 22$ & $0.27 \pm 0.04$ & $-55.30 \pm 1.43$ & $/$ \\
HYA $_{\text {GA }}$ & $424 \pm 32$ & $0.28 \pm 0.06$ & $-56.90 \pm 0.48$ & $59.22 \pm 8.18$ \\
\hline
\end{tabular}

The particle size distribution (PSD) value can reflect the homogeneity of liposome and hyalurosome samples [24]. In our study, both kinds of vesicles showed a good PSD value, lower than 0.3, demonstrating that the extrusion could be a suitable process to obtain uniform samples [25].

Concerning the $\zeta$ potential, all the prepared formulations were characterized by negative $\zeta$ potential values, in agreement with other published works [26,27]. This result was owing to the presence of phosphatidylcholine, which is a zwitterionic molecule containing the phosphate and choline functional groups. At $\mathrm{pH}$ 7.4, phosphatidylcholine shows the prevalence of negatively charged phosphate groups imparting a negative value to the liposome surface [28]. On the other side, in the presence of sodium hyaluronate, an increase of negativity $(p<0.05)$ was observed owing to its anionic nature and the interaction between the polymer and the choline groups of phosphatidylcholine. This result was in agreement with other findings [29] and can represent a proof of the presence of sodium hyaluronate on the vesicle surface.

\subsection{Vesicle Physical Stability}

Physical stability of liposomes and hyalurosomes is an important factor to predict the quality of formulations [30]. To determine vesicle stability, changes of size and PSD were monitored over a period of storage at $4-8{ }^{\circ} \mathrm{C}$ for 12 weeks. The vesicle variation in terms of size and PSD is reported in Figure 1a,b, respectively. Liposomes maintained their size until 4 weeks; after this period, an increase in size was observed $(p<0.05)$, reaching, for $L P$ and $L_{\mathrm{GA}}$, a final diameter equal to 439 and $470 \mathrm{~nm}$, respectively. No relevant changes with respect to size and PSD were detected for hyalurosomes, which showed a constant mean diameter and a homogeneous size distribution over the tested period. The higher stability of HYA and $\mathrm{HYA}_{\mathrm{GA}}$ could be ascribed to the highly negative $\zeta$ potential that probably limited the phenomenon of aggregation and precipitation of the vesicles during the storage period. In fact, as reported in the literature, higher values of $\zeta$ potential favor higher electrostatic repulsion among the vesicles and, consequently, a greater stability [31]. Moreover, the highest stability of hyalurosomes was in agreement with other previous works, suggesting that the aggregation of vesicles containing sodium hyaluronate is limited by the immobilizing effect of the polymer [12,20]. 


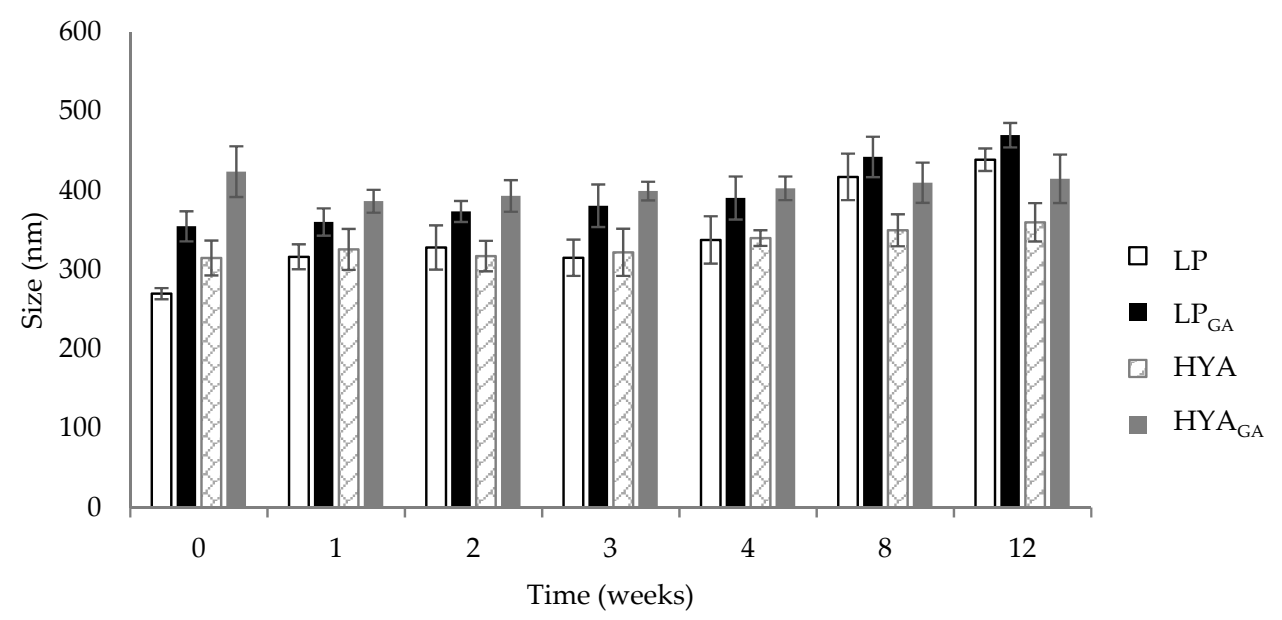

(a)

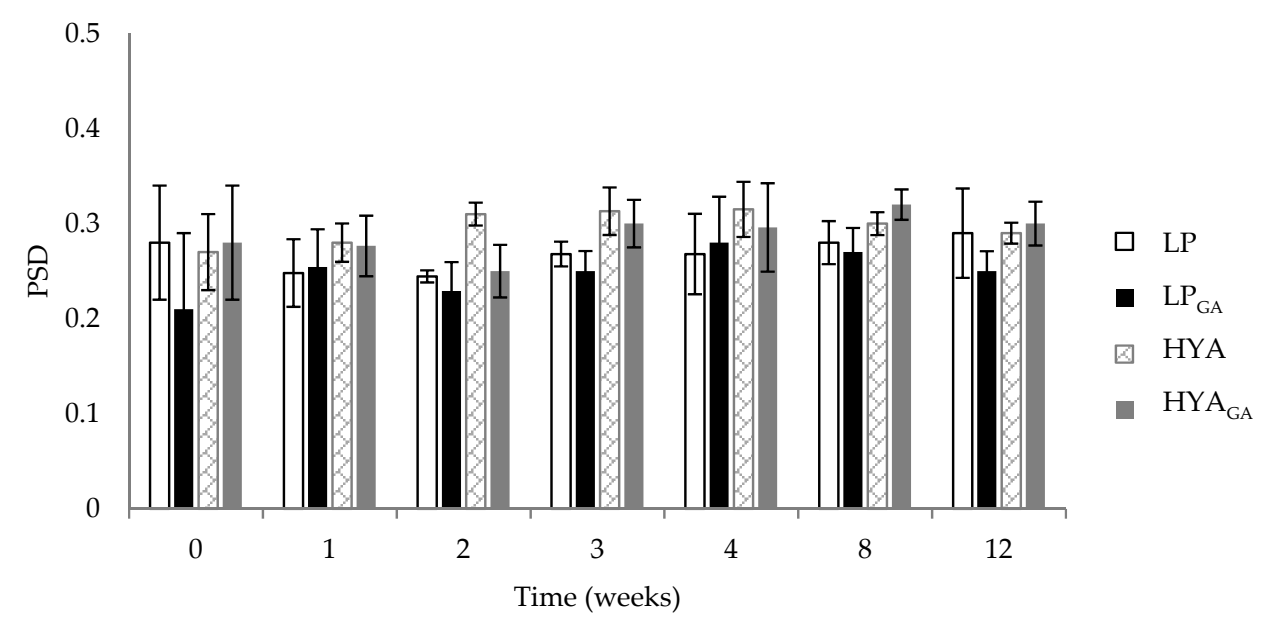

(b)

Figure 1. Variation of size (a) and particle size distribution (PSD) (b) of unloaded and loaded liposomes (LP) and hyalurosomes (HYA) during 12 weeks of storage at $4-8{ }^{\circ} \mathrm{C}$ (mean $\pm \mathrm{SD}, n=3$ ). GA, glycyrrhetinic acid.

\subsection{Determination of Encapsulation Efficiency}

Encapsulation efficiency (EE\%) represents a critical parameter in the evaluation of the potentiality of a delivery system [14]. The EE\% of GA was similar, with no statistical differences between $\mathrm{LP}_{\mathrm{GA}}$ and $\mathrm{HYA}_{\mathrm{GA}}(\sim 60 \%$, Table 1$)$, indicating the good ability of both vesicles to incorporate GA into the phospholipid bilayers. These EE\% values were similar to those obtained in the work of $\mathrm{Li}$ and colleagues [14], in which conventional liposomes and elastic vesicles containing GA were prepared. The authors observed EE\% values equal to $50.31 \pm 4.21 \%$ and $73.12 \pm 4.63 \%$ for conventional liposomes and elastic vesicles, respectively, and attributed the higher EE\% of elastic vesicles to the presence of sodium deoxycholate that favors GA incorporation into the lipid bilayers. Regarding the presence of sodium hyaluronate, we did not observe any impact of the polymer on $\mathrm{EE} \%$. This finding was in agreement with results previously reported by Castangia et al. [12]. In this work, the authors prepared liposomes and hyalurosomes containing the liquorice extract, obtained by percolation in ethanol of Glycyrrhiza glabra L. roots, or the raw glycyrrhizin. The authors reported no significant differences in the $\mathrm{EE} \%$ values of the liquorice extract and glycyrrhizin between liposomes and hyalurosomes. 


\subsection{In Vitro Release Studies from Liposomes and Hyalurosomes}

The effectiveness of a drug delivery system can be influenced by the release behavior of the active substance. Figure 2 shows the fractional amount of GA released from LP $\mathrm{GA}_{\text {and HYA }}$ GA as a function of time. As can be seen from Figure 2, a fast release of GA was observed in PBS/EtOH (7:3 v/v), reaching $88 \%$ and $73 \%$ of the total GA amount after 15 min for LP ${ }_{G A}$ and HYA ${ }_{G A}$, respectively. At this time point, the difference observed in the value of GA released from $\mathrm{LP}_{\mathrm{GA}}$ and HYA $\mathrm{GA}(p<0.05)$ was probably related to the presence of sodium hyaluronate on the vesicle surface, which influenced the GA partition between the vesicle bilayer and the release medium. However, after $30 \mathrm{~min}$, the release was no longer considerably affected by the type of vesicles. Considering that the first hours are decisive for the wound healing process [32], the fast release of GA could be useful for reaching its maximum drug amount at the wound site immediately after vesicle application, thus being advantageous to accelerate the tissue repair healing.

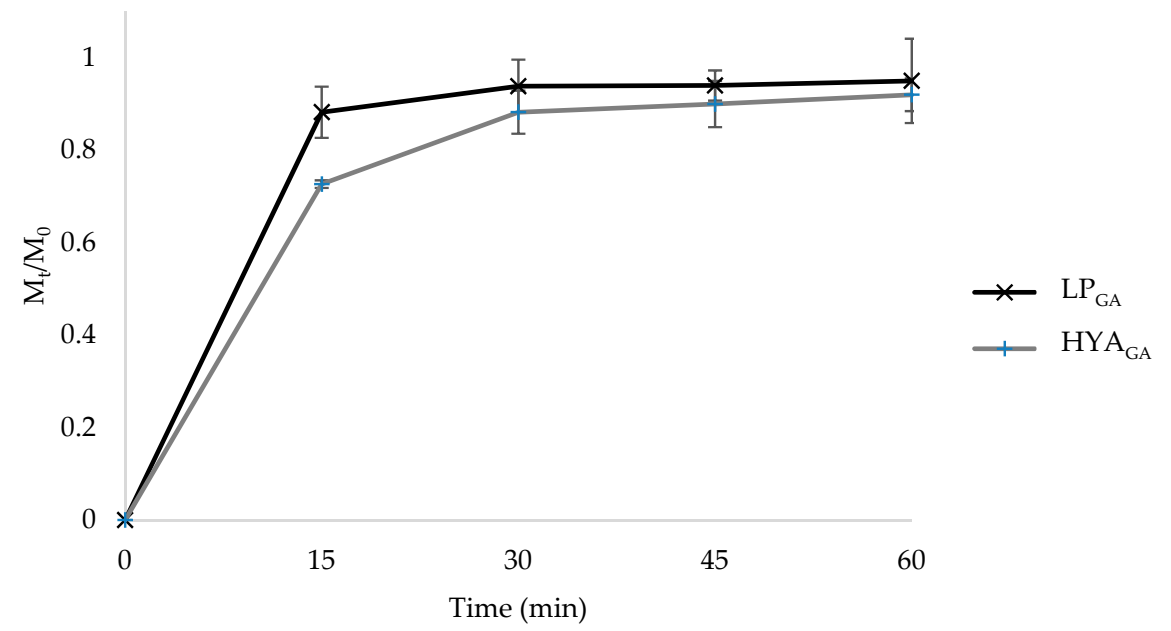

Figure 2. In vitro GA release in PBS/EtOH (7:3 v/v) from $\mathrm{LP}_{\mathrm{GA}}$ and $\mathrm{HYA}_{\mathrm{GA}}($ mean $\pm \mathrm{SD}, n=3)$.

\subsection{Biocompatibility of LPGA and HYAGA}

To assess the biocompatibility of GA-loaded vesicles, the viability of 3T3 fibroblasts was analyzed by MTT assay. It has been reported that GA can inhibit the proliferation of different cell lines [33]; therefore, it was investigated if 3T3 cell line viability was affected by GA itself, prior to testing LP $_{\mathrm{GA}}$ and HYA $_{G A}$. Fibroblasts were treated with GA concentrations ranging from 3 to $20 \mu \mathrm{g} / \mathrm{mL}$, corresponding to those contained in the vesicle suspensions tested for the MTT assay. The results reported in Table 2 show the absence of a toxic effect after treatment with GA, as viable population is superimposable to the control ones; cytotoxicity was rated based on cell viability relative to the control group, considering significant values below $95 \%$.

Table 2. Cell viability of $3 \mathrm{~T} 3$ cells after culture with different concentrations of GA for $24 \mathrm{~h}$. Results are shown in mean percentage respect to the controls taken as $100 \%$ (mean $\pm \mathrm{SD}, \mathrm{n}=3$ ).

\begin{tabular}{ccccc}
\hline & \multicolumn{4}{c}{ GA Concentration $(\mu \mathrm{g} / \mathrm{mL})$} \\
\cline { 2 - 5 } & $\mathbf{3 . 4}$ & $\mathbf{6 . 7}$ & $\mathbf{1 0}$ & $\mathbf{2 0}$ \\
\hline Viable cells $(\%)$ & $91.9 \pm 7.6$ & $88.0 \pm 8.5$ & $88.6 \pm 6.7$ & $95.4 \pm 6.6$ \\
\hline
\end{tabular}

Then, cells were treated with $\mathrm{LP}_{\mathrm{GA}}$ or $\mathrm{HYA}_{\mathrm{GA}}$ at different dilutions in order to obtain final concentrations of phosphatidylcholine and GA ranging from 50 to $300 \mu \mathrm{g} / \mathrm{mL}$ and 3 to $20 \mu \mathrm{g} / \mathrm{mL}$, respectively (Figure 3). The obtained data revealed that both types of vesicles are highly biocompatible up to $150 \mu \mathrm{g} / \mathrm{mL}$ phosphatidylcholine concentration. Interestingly, HYA $\mathrm{GA}$ did not exert any toxicity 
up to the maximum tested concentration of phosphatidylcholine $(300 \mu \mathrm{g} / \mathrm{mL})$. Moreover, $\mathrm{HYA}_{\mathrm{GA}}$ showed a superior biocompatibility with respect to $\mathrm{LP}_{\mathrm{GA}}$ when phosphatidylcholine concentrations were equal to 150 and $300 \mu \mathrm{g} / \mathrm{mL}(p<0.05)$.

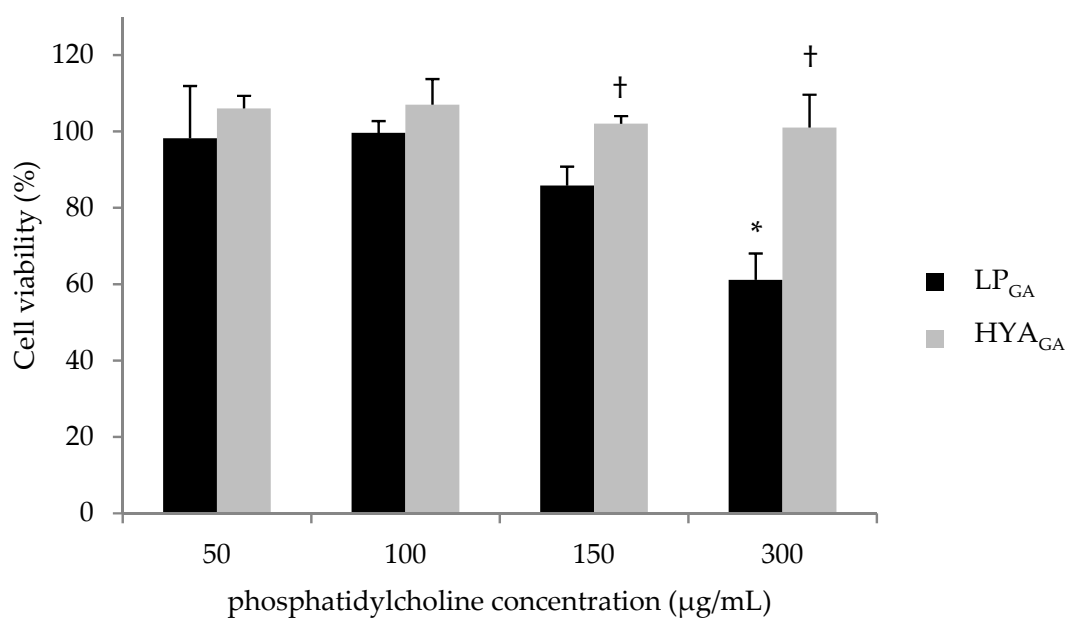

Figure 3. Viability of $3 \mathrm{~T} 3$ cells after different dilutions of $\mathrm{LP}_{\mathrm{GA}}$ and $\mathrm{HYA}_{\mathrm{GA}}$ treatment for $24 \mathrm{~h}$. Results are shown in mean percentage respect to the controls taken as $100 \%$ (mean $\pm \mathrm{SD}, n=3$ ) Significance indicated by ${ }^{*} p<0.05$ compared with the control and ${ }^{\dagger} p<0.05$ compared with $\mathrm{LP}_{\mathrm{GA}}$.

To deeply investigate the activity of the vesicles under test on cell proliferation, cell cycle analysis was performed by means flow cytometry. The results showed the absence of significant alteration in cell cycle progression. Moreover, $\mathrm{HYA}_{\mathrm{GA}}$ seem more promising again, as they are able to induce a moderate increase of cell percentage in S phase at both 100 and $150 \mu \mathrm{g} / \mathrm{mL}$ of phosphatidylcholine concentrations with respect to the controls; this could indicate a stimulating effect on fibroblast proliferation - useful and desirable in the contest of wound treatment (Figure 4). This result was in agreement with previous findings reporting the re-epithelising and tissue remodeling properties of sodium hyaluronate $[12,20,34]$.

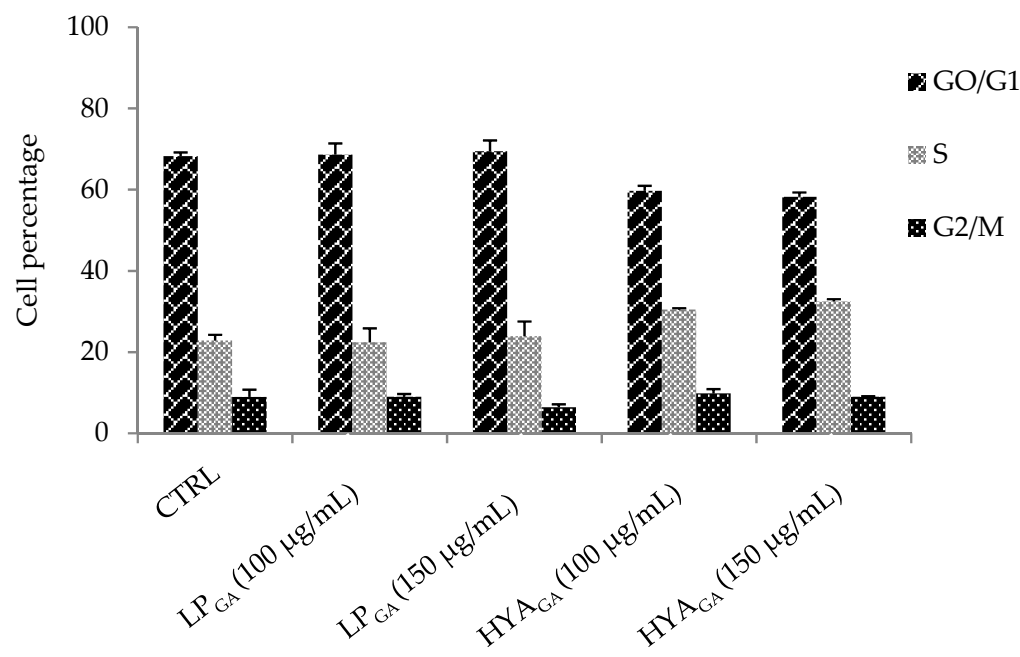

Figure 4. Cell cycle analysis of $3 \mathrm{~T} 3$ cells treated with $\mathrm{LP}_{\mathrm{GA}}$ or $\mathrm{HYA}_{\mathrm{GA}}$ (100 or $150 \mu \mathrm{g} / \mathrm{mL}$ phosphatidylcholine concentration) for $24 \mathrm{~h}$. The histograms report the percentage of cells in the different phases of the cell cycle, evaluated by flow cytometric assay. 


\subsection{In Vitro Release Studies from the Final Dressings}

The employment of dressings allowed to optimize the application of vesicle suspensions on skin wounds, to simplify self-medication, and consequently to increase patient compliance. Considering their ability to promote conformability to the wound area [35] and their physico-chemical properties, Spanish Broom, flax, and hemp dressings could be proposed as new biomaterials able to cover the wounds and to deliver at the wound site nanosystems carrying functional molecules such as GA.

Preliminary studies were conducted in order to evaluate the adsorption ability of the different dressings. For this purpose, Spanish Broom, flax, and hemp dressings $(2 \times 2 \mathrm{~cm})$ were impregnated with different volumes of vesicle suspensions ranging from 0.15 to $1 \mathrm{~mL}$. Impregnation of the dressings was considered completed after $15 \mathrm{~min}$ and the maximum volume efficiently adsorbed for all the dressings was found to be $0.5 \mathrm{~mL}$. This behavior is in agreement with our previous work [6].

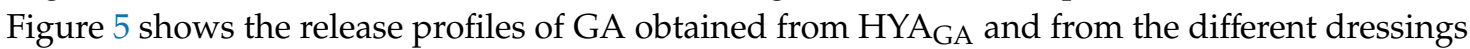

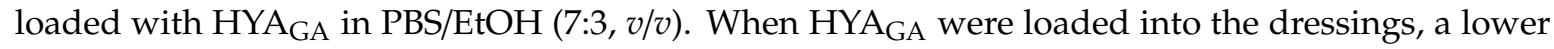
amount of GA was released in the first 30 min with respect to the free hyalurosome suspension $\mathrm{HYA}_{\mathrm{GA}}$ $(p<0.05)$. This result could probably be related to the diffusion of GA in the dressing environment, in addition to GA partition between the vesicle bilayer and the release medium or the dressing. However, the complete release of GA was also obtained after $60 \mathrm{~min}$ for the final dressings. Similar release profiles were observed with dressings loaded with $\mathrm{LP}_{\mathrm{GA}}$ (data not shown). These results indicated that, when vesicles were loaded into Spanish Broom, flax, and hemp dressings, the total GA amount loaded in the final formulations can be available at the wound site within 60 min from their application, thus favoring the wound healing process.

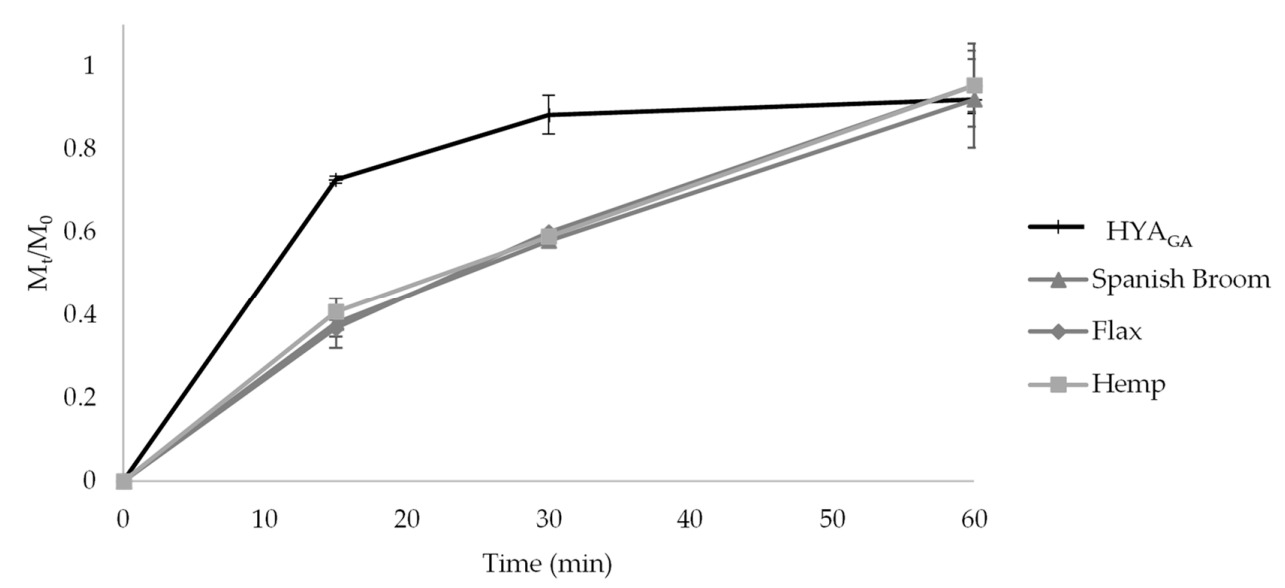

Figure 5. In vitro GA release in PBS:EtOH (7:3 v/v) from HYA $\mathrm{GA}_{\mathrm{A}}$ and from Spanish Broom, flax and hemp wound dressings loaded with $\mathrm{HYA}_{\mathrm{GA}}$ (mean $\pm \mathrm{SD}, n=3$ ).

\section{Materials and Methods}

\subsection{Materials}

L- $\alpha$-phosphatidylcholine from egg yolk, 18- $\beta$-glycyrrhetinic acid (GA), and all the solvents were purchased from Sigma-Aldrich (Milan, Italy). Sodium hyaluronate (molecular weight $=800-1200 \mathrm{kDa}$ ) was sourced from Farmalabor (Canosa di Puglia, Italy). Spanish Broom dressing was provided by Prof. Giuseppe Chidichimo, from University of Calabria (Arcavacata di Rende, CS, Italy). Flax and hemp dressings were obtained from Linificio e Canapificio S.r.l. (Villa D'Almè, Bergamo, Italy). All other chemicals were purchased from Carlo Erba (Milan, Italy). Mouse 3T3 fibroblast cells were from the American Type Culture Collection (ATCC; Rockville, MD, USA). All reagents for cell culture were obtained from Sigma-Aldrich (St. Louis, MO, USA), if not otherwise specified, and were ultrapure grade. Roswell Memorial Park Institute (RPMI-1640) medium, fetal bovine serum (FBS), and 
Dulbecco's phosphate-buffered saline (DPBS) were purchased from Gibco-Life Technologies (Carlsbad, CA, USA). All plastic supports were purchased from Falcon, BectonDickinson (Franklin Lakes, NJ, USA). Phosphate buffer solution at $\mathrm{pH} 7.4$ (PBS) was prepared with the following composition: $2.38 \mathrm{~g} / \mathrm{L}$ $\mathrm{Na}_{2} \mathrm{HPO}_{4} \times 12 \mathrm{H}_{2} \mathrm{O}, 0.19 \mathrm{~g} / \mathrm{L} \mathrm{KH}_{2} \mathrm{PO}_{4}, 8 \mathrm{~g} / \mathrm{L} \mathrm{NaCl}$. For GA determination, a phosphate buffer with $9.15 \mathrm{~g} / \mathrm{L} \mathrm{Na}_{2} \mathrm{HPO}_{4} \times 12 \mathrm{H}_{2} \mathrm{O}$, adjusted at $\mathrm{pH} 7.0$ with $\mathrm{H}_{3} \mathrm{PO}_{4}$, was also prepared.

\subsection{Liposome and Hyalurosome Preparation}

Liposomes were prepared by the film rehydration method followed by extrusion, reported by Uchino et al. [36] with some modifications. Briefly, L- $\alpha$-phosphatidylcholine $(300 \mathrm{mg})$ was dissolved in a mixture of $\mathrm{CHCl}_{3}-\mathrm{CH}_{3} \mathrm{OH}(10 \mathrm{~mL}, 9: 1 \mathrm{v} / \mathrm{v})$ in a round-bottomed flask and, subsequently, the organic mixture was evaporated using a rotatory evaporator (Buchi Rotavapor R-200, Flawil, Switzerland) under reduced pressure ( $80 \mathrm{mbar}$ ) at $55^{\circ} \mathrm{C}$ for $150 \mathrm{~min}$. The dry lipid film was then hydrated with $40 \mathrm{~mL}$ of PBS for $1 \mathrm{~h}$, obtaining a final phosphatidylcholine concentration equal to $7.5 \mathrm{mg} / \mathrm{mL}$. The resulting suspension was extruded 10 times through a polycarbonate membrane with a pore size of $100 \mathrm{~nm}$ (LiposoFast manual syringe extruder, Avestin Europe $\mathrm{GmbH}$, Mannheim, Germany) in order to reduce and homogenize vesicle size [25]. Hyalurosomes were obtained through rehydration of the lipid film with a sodium hyaluronate solution, prepared by dissolving the polymer in PBS $(0.5 \mathrm{mg} / \mathrm{mL})$ for $30 \mathrm{~min}$ under stirring at $200 \mathrm{rpm}$. For the preparation of the loaded vesicles, GA was solubilized in the organic phase at a concentration of $2 \mathrm{mg} / \mathrm{mL}$. The different formulations were named on the basis of their composition as follows: $\mathrm{LP}$ and $\mathrm{LP}_{\mathrm{GA}}$ for unloaded and loaded liposomes, respectively; HYA and HYA $_{\mathrm{GA}}$ for unloaded and loaded hyalurosomes, respectively.

\subsection{Vesicle Characterization}

Liposomes and hyalurosomes were characterized in terms of size, particle size distribution (PSD), and $\zeta$ potential. Size and PSD were measured by PCS (photon-correlation spectroscopy) using a Brookhaven 90-PLUS instrument (Brookhaven Instruments Corp., Holtsville, NY, USA) with He-Ne laser beam at a wavelength of $532 \mathrm{~nm}$ (scattering angle of $90^{\circ}$ ). Suspensions were diluted (1:500; $v / v)$ in ultrapure water (18.2 $\mathrm{M} \Omega \mathrm{cm}$, MilliQ apparatus by Millipore, Milford, MA, USA). $\zeta$ potential measurements were carried out at $25{ }^{\circ} \mathrm{C}$ on a Malvern Zetasizer 3000 HS instrument (Malvern Panalytical Ltd., Malvern, UK), after the same dilution.

\subsection{Vesicle Physical Stability}

The physical stability of the prepared liposomes and hyalurosomes was assessed by monitoring the size and the PSD over 12 weeks of storage at $4-8{ }^{\circ} \mathrm{C}$. For this study, aliquots of vesicle suspensions were diluted in ultrapure water $(1: 500 ; v / v)$ and the change of liposome and hyalurosome size and PSD index was measured using PCS.

\subsection{Determination of Encapsulation Efficiency}

To quantify the amount of GA not incorporated into the vesicles, a modification of the dialysis method previously described [37] was employed. Briefly, $3 \mathrm{~mL}$ of the liposome or hyalurosome suspensions were placed inside a Visking Tubo Dialysis membrane (Medicell International Ltd., London, UK) with a cut-off size of 14,000 Dalton. The tube was then immersed into $150 \mathrm{~mL}$ of PBS (external phase) and kept at $25^{\circ} \mathrm{C}$ for $48 \mathrm{~h}$ under stirring at $100 \mathrm{rpm}$. The free GA, separated from liposomes or hyalurosomes and contained in the external phase, was detected via the HPLC method. The chromatographic system was composed of a Shimadzu (Milan, Italy) LC-10ATVP chromatographic pump and a Shimadzu SPD-10AVP UV-vis detector set at $250 \mathrm{~nm}$. Separation was obtained on a Phenomenex (Torrance, CA, USA) Synergi Fusion-RP 80A (150 mm $\times 4.6 \mathrm{~mm}$ I.D., $5 \mu \mathrm{m})$ coupled to a Phenomenex (Torrance, CA, USA) SecurityGuard C18 guard cartridge $(4 \mathrm{~mm} \times 3.0 \mathrm{~mm}$ I.D., $5 \mu \mathrm{m})$. The mobile phase was a mixture of an aqueous phosphate buffer at $\mathrm{pH} 7.0$ and acetonitrile $(40: 60, v / v)$. The flow rate was $0.4 \mathrm{~mL} / \mathrm{min}$ and manual injections were made using a Rheodyne 7125 injector with a 
$20 \mu \mathrm{L}$ sample loop. Data processing was handled by means of a CromatoPlus computerized integration system (Shimadzu Italia, Milan, Italy). The calibration curve of concentration versus peak area ratio was plotted at a concentration range of $0.1-5 \mu \mathrm{g} / \mathrm{mL}$ and a good linearity was found $\left(R^{2}=0.998\right)$.

The encapsulation efficiency (EE) was calculated using the following equation:

$\mathrm{EE} \%=($ Total amount of GA-Amount in the external phase $) \times 100 /$ Total amount of GA

\subsection{In Vitro Release Studies from Liposomes and Hyalurosomes}

For this study, vesicle suspensions $(0.5 \mathrm{~mL})$ were placed in a beaker containing $10 \mathrm{~mL}$ of PBS and ethanol $(7: 3 \mathrm{v} / \mathrm{v})$ mixture, and then the system was put in a water bath at $32{ }^{\circ} \mathrm{C}$ with an agitation speed of $100 \mathrm{rpm}$. At predetermined time intervals, aliquots of the sample were taken from the medium, centrifuged at 14,500 rpm for $15 \mathrm{~min}$, and the supernatant was analyzed through HPLC [25]. The release of GA over the time was determined as $M_{t} / M_{0}$ (fractional amount), where $M_{t}$ represents the cumulative amount of GA released at each time and $\mathrm{M}_{0}$ the total GA mass into the vesicle suspensions.

\subsection{Cell Culture and Treatment}

3 T3 fibroblasts were maintained in RPMI 1640 medium, supplemented with 10\% FBS, 2 mM L-glutamine, $100 \mathrm{U} / \mathrm{mL}$ penicillin, and $100 \mu \mathrm{g} / \mathrm{mL}$ streptomycin, at $37^{\circ} \mathrm{C}$ and $5 \% \mathrm{CO}_{2}$. Cells were seeded at $1 \times 10^{4}$ cells $/ \mathrm{cm}^{2}$ in plastic wells and allowed to grow for one day before treatment. Specifically, cells were treated without (control) or with GA (dissolved in a mixture of PBS/EtOH 97:3 v/v) at different concentrations ranging from 3 to $20 \mu \mathrm{g} / \mathrm{mL}$. Loaded vesicles were tested at different dilutions corresponding to $50-300 \mu \mathrm{g} / \mathrm{mL}$ and $3-20 \mu \mathrm{g} / \mathrm{mL}$ concentration range of phosphatidylcholine and GA, respectively.

\subsubsection{Cell Viability Assay (MTT)}

To assess the in vitro toxicity of GA and of loaded vesicles, 3T3 cells seeded in 24-well culture plates were treated for $24 \mathrm{~h}$. MTT (3-(4,5-dimethylthiazol-2-yl)-2, 5-diphenyl tetrazolium bromide) stock solution was prepared as $2.5 \mathrm{mg} / \mathrm{mL}$ in PBS. Then, $0.02 \mathrm{~mL}$ of this solution was added to each well, and cells were incubated for four hours. Next, the supernatant was removed and the dark blue formazan crystals were dissolved in $1 \mathrm{~mL}$ of isopropanol. The absorbance at $570 \mathrm{~nm}$ (which reflects the relative viable cell number) was determined by UV-vis spectrophotometer (Kontron Uvikon 860, Augsburg, Germany).

\subsubsection{Cell Cycle Analysis}

DNA profiles of 3 T3 cells were obtained by flow cytometry according to Erba et al. [38]. Cells treated with $\mathrm{LP}_{\mathrm{GA}}$ and $\mathrm{HYA}_{\mathrm{GA}}$ at the indicated dilutions for $24 \mathrm{~h}$, were detached with $0.25 \%$ trypsin- $-0.02 \%$ EDTA solution and counted. Then, $1 \times 10^{6}$ cells were washed from growth medium and centrifuged at $240 \times \mathrm{g}$ for ten minutes. The pellet was suspended in $1 \mathrm{~mL}$ of a solution containing $0.1 \%$ trisodium citrate, $0.01 \%$ Igepal, $10 \mu \mathrm{g} / \mathrm{mL}$ of RNAse, and $50 \mu \mathrm{g} / \mathrm{mL}$ of propidium iodide (PI). After $30 \mathrm{~min}$ at $37^{\circ} \mathrm{C}$ in the dark, the isolated nuclei were analyzed by using a Bryte HS flow cytometer (Bio-Rad, Hercules CA, USA) equipped with a Xe/Hg lamp and a filter set to obtain an excitation at $488 \mathrm{~nm}$. PI fluorescence was collected on a linear scale at $600 \mathrm{~nm}$, and the DNA distribution was analyzed by the ModFit 5.0 software (Verity, Topsham, ME, USA).

\subsection{Preparation of Wound Dressings}

\subsubsection{Impregnation of Spanish Broom, Flax, and Hemp Dressings with Vesicle Suspensions}

The final wound dressings were prepared using three different supporting materials, Spanish Broom, flax, and hemp. Spanish Broom fibers were extracted by patented DiCoDe (digestion-compression-decompression) process [39], which provided fibers with a high cellulose 
content $(91.7 \pm 0.1 \%)$, excellent mechanical properties (tenacity $35.9 \pm 1.6 \mathrm{cN} /$ tex, strain at break $5.8 \pm 1.7 \%$ ), and good cyto-compatibility [7]. Flax and hemp cellulose content was $75.3 \pm 0.3 \%$ and $70 \%$, respectively $[6,40]$.

In order to obtain the final wound dressings, vesicles prepared, as reported in Section 3.2 were absorbed onto Spanish Broom, flax, and hemp dressings by impregnation [7], the most commonly used and convenient process for depositing nanosystems on fibers [41]. Preliminary studies were conducted in order to investigate dressing ability to adsorb vesicle suspensions. Specifically, Spanish Broom, flax, and hemp dressings were cut into $2 \times 2 \mathrm{~cm}$ pieces and different volumes of vesicle suspensions, ranging from 0.15 to $1 \mathrm{~mL}$, were deposited onto these samples. The ability of dressings to adsorb the vesicle suspension was evaluated for $1 \mathrm{~h}$. The developed dressings were then sealed in aluminum foil bags and stored at $4-8{ }^{\circ} \mathrm{C}$ until use.

\subsubsection{In Vitro Release Studies from Wound Dressings}

The different dressings, obtained as reported in Section 3.8.1, were placed in $10 \mathrm{~mL}$ of a mixture of PBS and ethanol $(7: 3 \mathrm{v} / \mathrm{v})$ and maintained at $32{ }^{\circ} \mathrm{C}$ under agitation $(100 \mathrm{rpm})$. At predetermined time intervals, aliquots of the sample were taken from the medium and analyzed through HPLC after centrifugation, as reported in Section 3.6.

\subsection{Statistical Analysis}

All the experiments were performed in triplicate. The results were expressed as mean \pm standard deviation (S.D.). For all the performed studies, Student's $t$-test was used to determine statistical significance. Differences were deemed significant for $p<0.05$.

\section{Conclusions}

In this study, Spanish Broom, flax, or hemp dressings for skin wound treatment were prepared by impregnation with liposomes or hyalurosomes loaded with GA, previously prepared through the film hydration method followed by extrusion. Liposomes and hyalurosomes differed for the presence of sodium hyaluronate, selected on the basis of its well-known role in skin wound healing. Liposomes and hyalurosomes of nanometric size and homogeneously dispersed were successfully prepared and efficiently loaded with GA. Hyalurosomes showed appropriate stability during the storage period, which can be correlated to the negative $\zeta$ potential, and allowed a fast and complete release of GA. Moreover, hyalurosomes were not cytotoxic on fibroblast up to higher concentration with respect to the liposomes. Both types of vesicles did not significantly impair cell cycle progression, but a moderate increase of $S$ phase cell percentage was observed after treatment with hyalurosomes, suggesting a stimulating effect on fibroblast proliferation-useful and desirable in the contest of wound treatment. Finally, GA was completely released within $60 \mathrm{~min}$ from the different dressings impregnated with hyalurosomes. Considering that the first hours are decisive for the wound healing process, this result could be promising to accelerate the skin repair. In conclusion, this study suggests that Spanish Broom, flax, or hemp materials impregnated with GA-loaded hyalurosomes could be considered new functional dressings for the treatment of skin wounds, even if only future in vivo studies will be able to definitely confirm this hypothesis.

Author Contributions: Conceptualization, T.C. and A.A.; methodology, A.A., G.F., and C.C.; validation, T.C.; investigation, A.A. C.C., and G.F.; data curation, T.C. and A.A.; writing-original draft preparation, T.C., A.A., C.C., and G.F.; writing-review and editing, T.C, A.A., B.L., and F.B.; supervision and project administration T.C. All authors have read and agreed to the published version of the manuscript.

Funding: This research received no external funding.

Acknowledgments: The authors are thankful to Giulia Mossa and Giorgio Rondi for their contribution to the work.

Conflicts of Interest: The authors declare no conflict of interest. 


\section{References}

1. Schreml, S.; Szeimies, R.M.; Prantl, L.; Landthaler, M.; Babilas, P. Wound healing in the 21st century. J. Am. Acad. Dermatol. 2010, 63, 866-881. [CrossRef] [PubMed]

2. Gainza, G.; Bonafonte, D.C.; Moreno, B.; Aguirre, J.J.; Gutierrez, F.B.; Villullas, S.; Pedraz, J.L.; Igartua, M.; Hernandez, R.M. The topical administration of rhEGF-loaded nanostructured lipid carriers (rhEGF-NLC) improves healing in a porcine full-thickness excisional wound model. J. Control. Release. 2015, 197, 41-47. [CrossRef] [PubMed]

3. Tenci, M.; Rossi, S.; Bonferoni, M.C.; Sandri, G.; Boselli, C.; Di Lorenzo, A.; Daglia, M.; Icaro Cornaglia, A.; Gioglio, L.; Perotti, C.; et al. Particulate systems based on pectin/chitosan association for the delivery of manuka honey components and platelet lysate in chronic skin ulcers. Int. J. Pharm. 2015, 509, 59-70. [CrossRef] [PubMed]

4. Uzun, M. A review of wound management materials. J. Text. Eng. Fash. Tech. 2018, 4, 53-59. [CrossRef]

5. Rajendran, S. Advanced Textiles for Wound Care, 2nd ed.; Woodhead Publishing: Cambridge, UK, 2018 ; p. 26.

6. Cerchiara, T.; Chidichimo, G.; Rondi, G.; Gallucci, M.C.; Gattuso, C.; Luppi, B.; Bigucci, F. Chemical composition, morphology and tensile properties of Spanish Broom (Spartium junceum L.) fibres in comparison with flax (Linum usitatissimum L.). Fibres Text. East. Eur. 2014, 22, 25-28.

7. Cerchiara, T.; Abruzzo, A.; Ñahui Palomino, R.A.; Vitali, B.; De Rose, R.; Chidichimo, G.; Ceseracciu, L.; Athanassiou, A.; Saladini, B.; Dalena, F.; et al. Spanish Broom (Spartium junceum L.) fibers impregnated with vancomycin- loaded chitosan nanoparticles as new antibacterial wound dressing: Preparation, characterization and antibacterial activity. Eur. J. Pharm. Sci. 2017, 99, 105-112. [CrossRef]

8. Hickey, R.J.; Pelling, A.E. Cellulose biomaterials for tissue engineering. Front. Bioeng. Biotechnol. 2019, 7, 45. [CrossRef]

9. Hung, C.F.; Hsiao, C.Y.; Hsieh, W.H.; Li, H.J.; Tsai, Y.J.; Lin, C.N.; Chang, H.H.; Wu, N.L. 18ß-glycyrrhetinic acid derivate promotes proliferation, migration and aquaporin-3 expression in human dermal fibroblasts. PLoS ONE 2017, 12, 1-14. [CrossRef]

10. Kao, T.C.; Shyu, M.H.; Yen, G.C. Glycyrrhizic acid and 18beta-glycyrrhetinic acid inhibit inflammation via PI3K/Akt/ GSK3beta signaling and glucocorticoid receptor activation. J. Agric. Food. Chem. 2010, 58, 8623-8629. [CrossRef]

11. Kalaiarasi, P.; Pugalendi, K.V. Protective effect of $18 \mathrm{~b}$-glycyrrhetinic acid on lipid peroxidation and antioxidant enzymes in experimental diabetes. J. Pharm. Res. 2011, 4, 107-111.

12. Castangia, I.; Caddeo, C.; Manca, M.L.; Casu, L.; Latorre, A.C.; Díez-Sales, O.; Ruiz-Saurí, A.; Bacchetta, G.; Fadda, A.M.; Manconi, M. Delivery of liquorice extract by liposomes and hyalurosomes to protect the skin against oxidative stress injuries. Carbohydr Polym. 2015, 134, 657-663. [CrossRef]

13. Liu, T.; Zhu, W.; Han, C.; Sui, X.; Liu, C.; Ma, X.; Dong, Y. Preparation of glycyrrhetinic acid liposomes using lyophilization monophase solution method: Preformulation, optimization, and in vitro evaluation. Nanoscale Res. Lett. 2018, 13, 324. [CrossRef] [PubMed]

14. Li, S.; Qiu, Y.; Zhang, S.; Gao, Y. Enhanced transdermal delivery of $18 \beta$-glycyrrhetic acid via elastic vesicles: In vitro and in vivo evaluation. Drug Dev. Ind. Pharm. 2012, 38, 855-865. [CrossRef] [PubMed]

15. Jia, Y.; Zhang, H.; Yang, S.; Xi, Z.; Tang, T.; Yin, R.; Zhang, W. Electrospun PLGA membrane incorporated with andrographolide-loaded mesoporous silica nanoparticles for sustained antibacterial wound dressing. Nanomedicine (Lond) 2018, 13, 2881-2899. [CrossRef] [PubMed]

16. Pierre, M.B.; Dos Santos, M.; Costa, I. Liposomal systems as drug delivery vehicles for dermal and transdermal applications. Arch. Dermatol Res. 2011, 303, 607-621. [CrossRef] [PubMed]

17. Sharma, J.; Lizu, M.; Stewart, M.; Kyle, Z.; Yang, L.; Rajat, C.; Xingru, Y.; Zhanhu, G.; Evan, K.W.; Suying, W. Multifunctional nanofibers towards active biomedical therapeutics. Polymers. 2015, 7, 186-219. [CrossRef]

18. Zehao, L.; Meifeng, L.; Huijuan, W.; Song, D. Increased cutaneous wound healing effect of biodegradable liposomes containing madecassoside: Preparation optimization, in vitro dermal permeation, and in vivo bioevaluation. Int. J. Nanomed.. 2016, 11, 2995-3007.

19. Castangia, I.; Nácher, A.; Caddeo, C.; Valenti, D.; Fadda, A.M.; Díez-Sales, O.; Ruiz-Saurí, A.; Manconi, M. Fabrication of quercetin and curcumin bionanovesicles for the prevention and rapid regeneration of full-thickness skin defects on mice. Acta Biomater. 2014, 10, 1292-1300. [CrossRef] 
20. Manca, M.L.; Castangia, I.; Zaru, M.; Nacher, A.; Valenti, D.; Fernandez-Busquets, X.; Fadda, A.M.; Manconi, M. Development of curcumin loaded sodium hyaluronate immobilized vesicles (hyalurosomes) and their application on prevention and rapid restoring of mouse skin wound. Biomaterials. 2015, 71, 100-109. [CrossRef]

21. Chen, W.Y.J.; Abatangelo, G. Functions of hyaluronan in wound repair. Wound Repair Regen. 1999, 7, 79-89. [CrossRef]

22. Voss, G.T.; Gularte, M.S.; Vogt, A.G.; Giongo, J.L.; Vaucher, R.A.; Echenique, J.V.Z.; Soares, M.P.; Luchese, C.; Wilhelm, E.A.; Fajardo, A.R. Polysaccharide-based film loaded with vitamin C and propolis: A promising device to accelerate diabetic wound healing. Int. J. Pharm. 2018, 552, 340-351. [CrossRef] [PubMed]

23. Cerchiara, T.; Giordani, B.; Melgoza, L.M.; Prata, C.; Parolin, C.; Dalena, F.; Abruzzo, A.; Bigucci, F.; Luppi, B.; Vitali, B. New spanish broom dressings based on vitamin E and Lactobacillus plantarum for superficial skin wounds. J. Drug Deliv. Sci. Tech. 2020, 56, 101499. [CrossRef]

24. Ghorbanzade, T.; Jafari, S.M.; Akhavan, S.; Hadavi, R. Nano-encapsulation of fish oil in nano-liposomes and its application in fortification of yogurt. Food Chem. 2017, 216, 146-152. [CrossRef] [PubMed]

25. Abruzzo, A.; Giordani, B.; Parolin, C.; Vitali, B.; Protti, M.; Mercolini, L.; Cappelletti, M.; Fedi, S.; Bigucci, F.; Cerchiara, T.; et al. Novel mixed vesicles containing lactobacilli biosurfactant for vaginal delivery of an anti-Candida agent. Eur. J. Pharm. Sci. 2018, 112, 95-101. [CrossRef]

26. Perttu, E.K.; Kohli, A.G.; Szoka, F.C. Inverse-phosphocholine lipids: A remix of a common phospholipid. J. Am. Chem. Soc. 2012, 134, 4485-4488. [CrossRef]

27. Giordani, B.; Costantini, P.E.; Fedi, S.; Cappelletti, M.; Abruzzo, A.; Parolin, C.; Foschi, C.; Frisco, G.; Calonghi, N.; Cerchiara, T.; et al. Liposomes containing biosurfactants isolated from Lactobacillus gasseri exert antibiofilm activity against methicillin resistant Staphylococcus aureus strains. Eur J. Pharm. Biopharm. 2019, 139, 246-252. [CrossRef]

28. Scherer, P.G.; Seelig, J. Electric charge effects on phospholipid headgroups. Phosphatidylcholine in mixtures with cationic and anionic amphiphiles. Biochemistry 1989, 28, 7720-7728. [CrossRef]

29. Franzé, S.; Marengo, A.; Stella, B.; Minghetti, P.; Arpicco, S.; Cilurzo, F. Hyaluronan-decorated liposomes as drug delivery systems for cutaneous administration. Int. J. Pharm. 2018, 535, 333-339. [CrossRef]

30. Liang, T.; Guan, R.; Shen, H.; Xia, Q.; Liu, M. Optimization of conditions for cyanidin-3-O-Glucoside (C3G) nanoliposome production by response surface methodology and cellular uptake studies in Caco-2 cells. Molecules 2017, 22, 457. [CrossRef]

31. Dong, Y.; Feng, S.S. Methoxy poly(ethylene glycol)-poly(lactide) (MPEG-PLA) nanoparticles for controlled delivery of anticancer drugs. Biomaterials 2004, 25, 2843-2849. [CrossRef]

32. Marin, Ş.; Albu Kaya, M.G.; Ghica, M.V.; Dinu-Pîrvu, C.; Popa, L.; Udeanu, D.I.; Mihai, G.; Enachescu, M. Collagen-polyvinyl alcohol-indomethacin biohybrid matrices as wound dressings. Pharmaceutics 2018, 10, 224. [CrossRef] [PubMed]

33. Roohbakhsh, A.; Iranshahy, M.; Iranshahi, M. Glycyrrhetinic acid and its derivatives: Anti-cancer and cancer chemopreventive properties, mechanisms of action and structure- cytotoxic activity relationship. Curr. Med. Chem. 2016, 23, 98-517. [CrossRef] [PubMed]

34. Manuskiatti, W.; Maibach, H.I. Hyaluronic acid and skin: Wound healing and aging. Int. J. Dermatol. 1996, 35, 539-544. [CrossRef] [PubMed]

35. Dealey, C. The care of wounds: A Guide for Nurses, 4th ed.; Wiley-Blackwell: Oxford, UK, 2012.

36. Uchino, T.; Lefeber, F.; Gooris, G.; Bouwstra, J. Physicochemical characterization of drug-loaded rigid and elastic vesicles. Int. J. Pharm. 2011, 412, 142-147. [CrossRef]

37. Frank, K.J.; Westedt, U.; Rosenblatt, K.M.; Holig, P.; Rosenberg, J.; Magerlein, M.; Brandl, M.; Fricker, G. Impact of FaSSIF on the solubility and dissolution-/ permeation rate of a poorly water-soluble compound. Eur. J. Pharm. Sci. 2012, 47, 16-20. [CrossRef]

38. Erba, E.; Ubezio, P.; Pepe, S.; Vaghi, M.; Marsoni, S.; Torri, W.; Mangioni, C.; Landoni, F.; D’Incalci, M. Flow cytometric analysis of DNA content in human ovarian cancers. Br. J. Cancer 1989, 60, 45-50. [CrossRef]

39. Gabriele, B.; Cerchiara, T.; Salerno, G.; Chidichimo, G.; Vetere, M.V.; Alampi, C.; Gallucci, M.C.; Conidi, C.; Cassano, A. A new physical-chemical process for the efficient production of cellulose fibers from Spanish broom (Spartium junceum L.). Bioresour. Technol. 2010, 101, 724-729. [CrossRef] 
40. Quaglierini, C. Chimica Delle Fibre Tessili; Zanichelli: Bologna, Italy, 2012; p. 114.

41. Ripoll, L.; Bordes, C.; Etheve, S.; Elaissari, A.; Fessi, H. Cosmeto-textile from formulation to characterization: An overview. e-Polymers 2010, 40,1-34. [CrossRef]

Sample Availability: Samples of the compounds are available from the authors.

(C) 2020 by the authors. Licensee MDPI, Basel, Switzerland. This article is an open access article distributed under the terms and conditions of the Creative Commons Attribution (CC BY) license (http://creativecommons.org/licenses/by/4.0/). 